\title{
Stiff Sedimentary Clays-Genesis and Engineering Behaviour
}

\section{Editorial}

Welcome back to the second issue of the journal dedicated to the Géotechnique Symposium in Print for 2007. In the February issue we presented nine papers dealing with a wide range of issues in the London Clay formation. In this issue we broaden our scope to consider the behaviour of stiff sedimentary clays from a considerable range of other formations in various parts of Europe; we have theoretical and laboratory studies investigating fundamental concepts; and we deal with a range of engineering problems including studies of dams, retaining walls and radioactive waste repositories.

The individual papers develop some of the key themes which we intend to explore in greater depth at the symposium meeting on 14th May 2007. No doubt you will have noticed the role played by better geological understanding in some of the engineering studies, aided by improved field and laboratory techniques. Alongside these developments are innovations in our conceptual understanding of stiff clay behaviour and in the engineering solutions being applied to stiff clay sites. Taken together, these developments mark a major step forward in our approach to stiff clays.

We are of course greatly indebted to the authors of the papers for sharing their insights. An enormous amount of hard work has been expended on the papers with reviews and revisions being undertaken to a tight timescale. I would like to extend my personal thanks to all who have contributed.

\section{THE SYMPOSIUM MEETING}

As I mentioned in the February issue, the Symposium in Print meeting will be held on 14th May at the Institution of Civil Engineers in London. We expect the meeting to be very well attended and so I would encourage you to indicate your interest as soon as possible by emailing the ICE conference team at conferences@ice.org.uk. This will ensure that registration documents are sent to you as soon as these become available.

The Géotechnique subcommittee, together with Thomas Telford and ICE, are working hard to make the meeting as productive and lively as possible. We have two excellent keynote speakers, Professor Richard Chandler and Dr Brian Simpson. The discussion sessions will be chaired by a team of leading practitioners who will seek to draw out key ideas and follow up the points which we hope you will contribute. We intend to have technical poster presentations and relevant technical displays to inspire further ideas in the breaks during the day. Without doubt it will be a landmark event_-don't miss it!

And so without further ado I commend to you the second group of Symposium in Print papers and technical notes. I am confident that you will find much to interest and inspire. Perhaps also you will draw different conclusions from those of some of the authors or will want to extend their lines of argument. The symposium will be the ideal forum to discuss these observations and I look forward to meeting you there. 